[Bull. Agr. Chem. Soc. Japan, Vol. 22, No. 1, 6 10, 1958]

\title{
On the Metabolism of D-Glucuronic Acid by Pseudomonas ovalis
}

\author{
Part II. Metabolic Pathway* \\ By Toshinobu Asar and Seiichi Nasuno \\ Institute of Applied Microbiology, University of Tokyo \\ Received August 30, 1957
}

\begin{abstract}
From the results obtained by the method of successive adaptation and paper chromatography of reaction mixtures by intact cells, it was presumed that D-glucuronic acid was first converted through D-galacturonic acid to 5-keto-L-galactonic acid and then further oxidized. The accumulation of pyruvic acid was observed in the reaction mixtures under aerobic incubation when the enzyme system was blocked with sodium arsenite. Moreover, $\alpha$-ketoglutaric acid was also found in the reaction mixtures with D-glucuronic or D-galacturonic acid as a substrate under aerobic incubation. Resting cells of the tested organisms showed the ability to oxidize all members of Krebs' tricarboxylic acid cycle, pyruvic and acetic acids. It is therefore proposed that the oxidation of D-glucuronic acid by Pseudomonas ovalis assumes the following pathway:

D-glucuronic acid $\longrightarrow$ D-galacturonic acid $\longrightarrow$ 5-keto-L-glactonic acid $\longrightarrow$ unknown $\longrightarrow$ pyruvic acid $\longrightarrow$ Krebs' tricarboxylic cycle $\longrightarrow \mathrm{CO}_{2}+\mathrm{H}_{2} \mathrm{O}$
\end{abstract}

\section{INTRODUCTION}

Many informations on the metabolism of D-glucuronic acid by animal tissue enzymes have long appeared during the past years. Several pathways involving the metabolic conversion of glucuronolactone to $\mathrm{L}$-xylulose and D-ribose have been reported by Enklewitz'), Touster2) and Horecker3). Recently, Rabinowitz and Sal14) obtained the result that the particle free enzyme system of rat kidney yielded approximately $12 \%$ of $\mathrm{CO}_{2}$ which was predominantly derived from the sixth position of carbon of glucuronolactone and D-glucuronic acid. However, it has scarcely

* The present work was aided by a grant in aid defrayed from the Scientific Research Fund of the Ministry of Education.

1) M. Enklewitz and M. Lasker, J. Biol. Cbem., 110, 443 (1953).

2) O. Touster, R. H. Mutcheson and L. Rice, J. Biol. Chem., 215, 677 (1955).

3) B. L. Horecker, P. Z. Smyrnoitis and J. E. Seegmiller, J. Biol. Chem., 193, 383 (1951).

4) J. L. Rabinowitz and T. Sall, Biochem. Biopbys, Acta, 23, 289 (1957) been known on the metabolic pathway of D-glucuronic acid by microorganisms.

Cohens) reported that $E$. coli $\mathrm{K} 12$ strain adapted to D-glucuronic acid did not produce $\mathrm{D}$-xylose. The same result was obtained by Heald6) with coli-form bacteria. Heald7) also showed that formic, acetic and lactic acids were found as the products of fermentation from D-glucuronic acid.

Payne ${ }^{8)}$ suggested that dried cells of Serratia marcescens grown on glucose minimal medium and adapted to D-glucuronic acid yielded a 1,6-" ester" linked dihexuronic acid from buffered D-glucuronic acid. This substance might be supposed to be an intermediate in the oxidative metabolism of D-glucuronic acid by this bacteria. He also discussed that D-galacturonic acid was isomerized to D-glucuronic acid before being metabolized $\tilde{S}$. marcescens.

5) S. S. Cohen, J. Biol. Chem., 177, 607 (1949).

6) P.J. Heald, Bivchem. J. (London), 50, 503 (1952).

7) P.J. Heald, Biochem. J. (London), 52, 378 (1952)

8) W J. Payne, J. Bact., 72, 834 (1956). 
In contradiction to this hypothesis, Watanabe and Arai9) ascertained that D-glucuronic acid was isomerized to D-galacturonic acid and then was converted to 5-keto-L-galactonic acid before being metabolized by strain K 12 of $E$. coli.

In this paper we present a presumable pathway of the oxidation of D-glucuronic acid by $P$ s. ovalis $40 \mathrm{~F}$ in which D-glucuronic acid was converted to 5-keto-L-galactonic acid via $D$-galacturonic acid and was oxidized through pyruvic acid and Kreb's tricarboxylic acid cycle to $\mathrm{CO}_{2}$ and $\mathrm{H}_{2} \mathrm{O}$.

\section{EXPERIMENTAL}

The cell preparation adapted to D-glucuronic acid and the mannometric procedures were the same as previously described ${ }^{10)}$.

The paper chromatographical techniques were employed to detect the intermediary products in the oxidation of D-galacturonic acids. The papers were developed by the descending method with upper layer of a solvent mixture consisting of 4 volumes of $n$ butanol, 1 volume of acetic acid and 5 volumes of water. As a reagent for the detection of reducing sugars and reducing sugar acids, 3\% n-butanol solution of $p$-anisidine hydrochloride was used. To detect organic acids derived from D-glucuronic acid, $1 \%$ alcohol solution of Brom Phenol Blue was applied. Keto-acids such as $\alpha$-ketoglutaric and pyruvic acids were derived to the 2,4-dinitrophenylhydrazones of them in order to observe yellow spots on the developed paper. They were always compared with authentic samples developed simultaneously.

Aerovic and anaerobic incubations containing a large amount of substrate with intact cell suspension were run to catch intermediary products in the oxidation of D-glucuronic and D-galacturonic acids and were tested quantitatively by the paper chromatographical methods at the interval of half an hour.

The reaction mixtures were prepared to contain $1.5 \mathrm{mM}$ substrate as sodium salt, $30 \mathrm{ml}$ of $\mathrm{M} / 20$ phosphate buffer at $\mathrm{pH} 6.0$ and $30 \mathrm{ml}$ of bacterial suspension containing $360 \mathrm{mg}$ dried cells. Under anaerobic incubation, the atmosphere in the vessel was exchanged with $\mathrm{N}_{2}$ gas.

9) M. Watanabe and M. Arai, Lecture delivered at the annual Meeting of Japanese Biochemical Soclety, Nov. 2 (1955).

10) T. Asai and $S$, Nasuno, This Bulletin, 22, 1 (1958)
Spot tests ${ }^{11}$ ) were applied to check formic and acetic acids in the reaction mixtures after incubation.

In order to accumulate pyruvic acid by blocking enzyme system, sodium arsenite in a concentration of $10^{-3} \mathrm{M}$ was used with the substrate of D-glucuronic or D-galacturonic acid.

A successive adaptation method was used to support the fact that D-galacturonic and 5-keto-L-galacturonic acids were the intermediary products in the metabolic sequences of D-glucuronic acid degradation. Furthermore, the ability to oxidize several substances which were presumed as intermediates, all members of Krebs' tricarboxylic acid cycle, pyruvic and acetic acids were tested by the respirometory.

5-Keto-L-galactonic acid was prepared by the method of Ehrlich and Gutterman ${ }^{12)}$. 2-Keto-D-galactonic acid was kindly supplied by Assist. Prof. K. Aida of our laboratory. The other chemicals used were commercial products

\section{RESUTL AND DISCUSSION}

The reaction mixture, which was incubated for 2 hours anaerobically with D-glucuronic acid as a substrate, was centrifuged after it was deprotenized by adding 50\% trichloroacetic acid. Its supernatant was spotted on the paper and developed by the descending method. Four spots were found after spraying with $3 \% n$-butanol solution of $p$-anisidine hydrochloride and their $R_{F}$ values were 0.34 , $0.17,0.18$ and 0.23 respectively. The former two were brown, the third was pink and the fourth was yellow. They corresponded to glucuronolactone, D-glucuronic, D-galacturonic and 5-keto-L-galactonic acids, although the existence of glucuronolactone was doubtful by spraying with $1 \%$ alcohol solution of Brom Phenol Blue. Furthermore, the spot of 5-keto-L-galactonic acid was also observed in the reaction mixture containing D-galacturonate as a substrate under same condition.

The method of successive adaptation by intact cells was applied to ratify that these two substances are intermediary metabolites by testing organism adapted to D-glucuronic acid. The result is shown in Figure 1.

11) F. Feigl, Spot Tests II, p. 245, 247 (1954).

12) F. Ehrlich and R. Gutterman, Ber., 67, 573 (1934). 


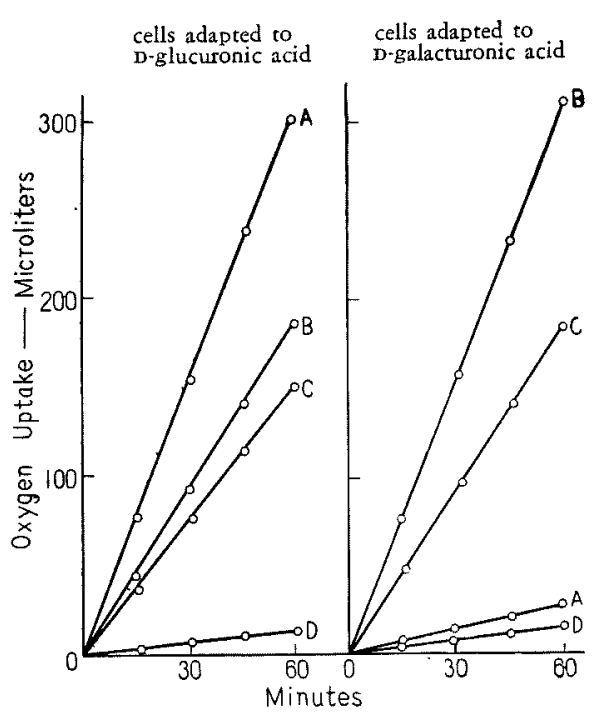

FIG. 1. Successive Adaptation to D-Glucuronic (A), D-Galacturonic (B), 5-Keto-L-Galactonic (C) and 2-Keto-D-Galactonic Acid (D).

Although both D-galacturonic and 5-ketoL-galactonic acids were oxidized after short lag periods by the cells not adapted to D-glucuronic acid, they were immediately oxidized without lag periods by the cells adapted to D-glucuronic acid. And furthermore, D-glucuronic acid was not oxidized, but D-galacturonic and 5-keto-L-galactonic acids were rapidly oxidized by the cells adapted to Dgalacturonic acid. Nor was 2-keto-D-galactonic acid completely oxidized by the cells adapted to either D-glucuronic or D-galacturonic acid.

The primary-stage of conversion of $\mathrm{D}$ glucuronic acid by $P$ s. ovalis appeared to be very similar with the result obtained by $E$. coli which was reported by Watanabe and Arai ${ }^{13)}$.

Several sugars and sugar acids being anticipated as intermediary products in the oxidation of D-glucuronic acid were checked by the mannometric method (Fig. 2). In addition to this, these tested sugars were not detected in the reaction mixture containing

\footnotetext{
13) M. Watanabe and M. Arai, Lecture delivered at the Symopsium of Enzyme Chemitry, July 24 (1956).
}

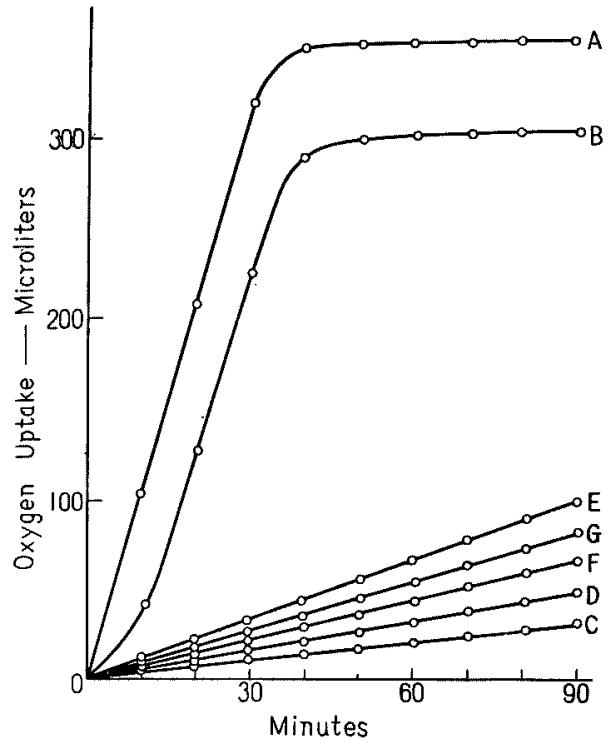

FIG. 2. The Oxidation of Glucose (A), Gluconic (B), 2-Ketogluconic (C) Acids, Galactose (D), Arabinose $(E)$, Xylose (F) and Ribose (G).

either D-glucuronic or D-galacturonic acid as a substrate, so from these experiments it seemed that D-arabinose, D-xylose and Dribose have no such possibility. L-Xylulose and D-ribose have been reported as metabolites by Enklewitz'), Touster ${ }^{2)}$ and Horecker ${ }^{3)}$. Heald?) showed that cells grown on D-glucuronic acid could not ferment galactose, xylose and arabinose by coli-form bacteria. Hough and Pridham ${ }^{14)}$ reported that no evidence was obtained for the conversion of the lactone of D-glucuronic acid to D-xylose by decarboxylation process with plum mesocarp tissues.

In order to catch the intermediary products in the rather terminal stage of metabolic pathway of D-glucuronic acid, reaction mixtures containing materials the same as those used in anaerobic incubation were incubated under aerobic condition. Samples of $10 \mathrm{ml}$ were taken at 15 minutes intervals and mixed with equal volumes of acetone to stop the

14) L. Hough and J.B. Pridham, Arch. Biocbem. and Biopbys, 59, 17 (1955). 
reaction. The samples were centrifuged and a part of supernatant from each vessel was tested to detect acetic and formic acids by the technique of spot tests, but these volatile acids could not be found contrary to Heald's report7). Another part of the supernatant was taken to prepare 2,4-dinitrophenylhydrazones of keto acids to apply chromatography. The $n$-butanol, acetic acid solvent was permitted to irrigate the chromatograms. Since, 2, 4-dinitrophenylhydrazone of $\alpha$ ketoglutaric acid was detected in a sample at 30 minutes, $\alpha$-ketoglutaric acid was supposed to be a possible intermediate of D-glucuronic acid metabolism.

The reaction mixtures containing either $D \cdot g l$ lucuronic or D-galacturonic acid as a substrate and sodium arsenite as a inhibitor were treated by the procedure as same as that of aerobic incubation mixtures. 2,4Dinitrophenylhydrazone of pyruvic acid was detected on the paper chromatogram, so pyruvic acid was also ascertained as a metabolic intermediate of the degradation of $\mathrm{D}^{-}$ glucuronic acid.

It has been investigated rather well that genus Pseudomonas have the enzymes of the Krebs' tricarboxylic acid cycle. According to Campbell and Stokes'5), and Campbell and Smith ${ }^{16)}$, both resting and dried cells of $P$ s. aeruginosa possess the enzymes necessary for the oxidation of compounds of the tricarboxylic acid cycle. They revealed that the limiting factor in the immediate utilization of these intermediates by resting cells was the impermeability of the cell membranes. Robinson and Katznelson ${ }^{17)}$ reported that all the enzymes of the tricarboxylic acid cycle, with the exception of oxalosuccinic acid decarboxylase, were detected in sonic extracts of Ps. nigrificans.

15) J. J. R Campbell and F. N. Stokes, J. Biol. Chem., 190. 853 (1951).

16) J. J. R. Campbell and R. A. Smith, Canad. J. Microbiol.. 2. 433 (1956).

17) J. Robinson and H. Katznelson, Canad. J. Microbiol,, 2, 723 (1956).
Resting cells harvested from a glucose medium and adapted to D-glucuronic acid had no ability to attack cis-aconitic, citric

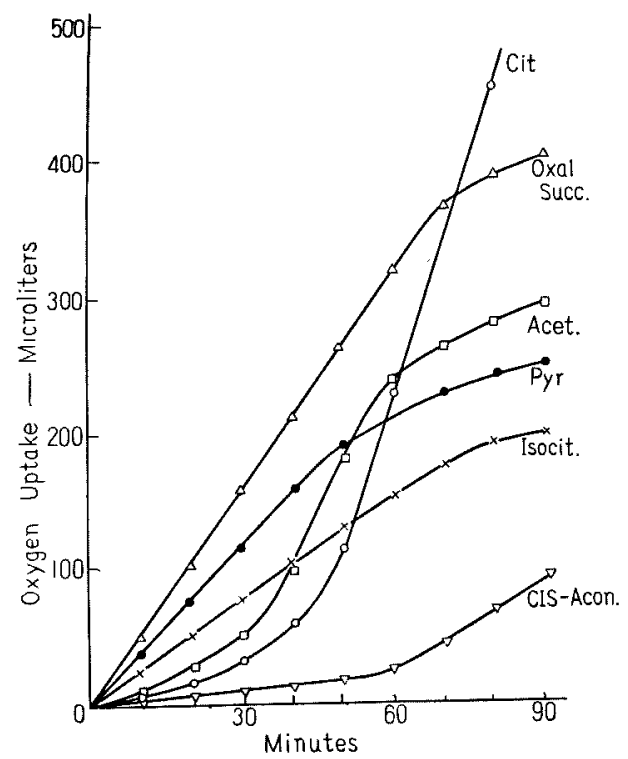

FIG. 3. The Oxidation of Citric, cis-Aconitic, iso-Citric, Oxaloacetic, Acetic and Pyruvic Acids.

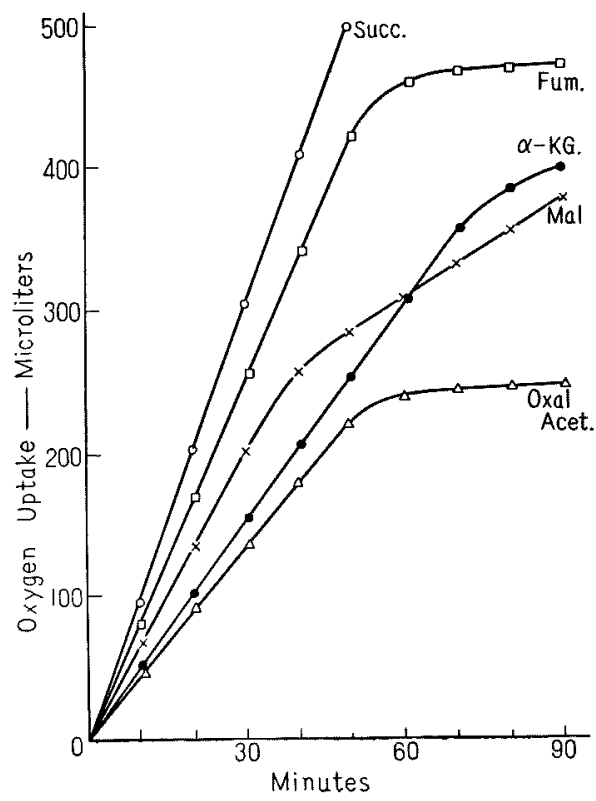

FIG. 4. The Oxidation of $\alpha$-Ketoglutaric, Succinic, Fumaric, Malic and Oxaloacetic Acids. 
and acetic acids immediately (Fig. 3 and 4). However, activity was demonstrated with other members of the tricarboxylic acid cycle and pyruvic acid. The presence of the enzymes necessary for the oxidation of the members of tricarboxylic acid cycle in the cells of Ps. ovalis points to the constitutive nature of the enzymes involved.

It is now known that $P$ s. ovalis oxidizes D-glucuronic acid by way of D-galacturonic and 5-keto-L-galactonic acids. Since pyruvic and $\alpha$-ketoglutaric acids were ascertained as intermediates in the oxidation of D-glucuronic acid, it is likely that the oxidation of these intermediates are of supreme importance as a means of oxidizing D-glucuronic acid by 'way of the Krebs' tricarboxylic acid cycle. As there is no evidence where esterification of phosphate does occur, it is therefore, vague to find now 5-keto-L-galactonic acid degradates to pyruvic acid. However, synthesizing the results obtained above, a presumable pathway of the oxidation of D-glucuronic acid by Ps. ovalis was strongly supposed as shown in Figure 5.

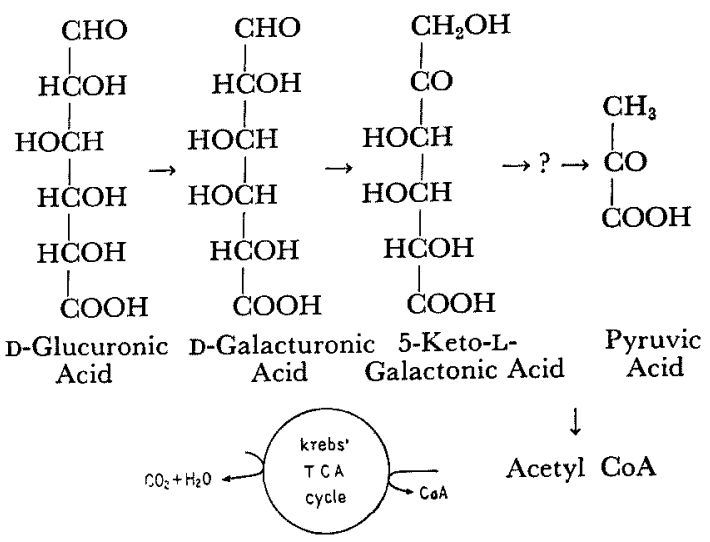

Fig. 5. Presumable Pathway of D-Glucuronic Acid Oxidation by $P$ seudomonas ovalis $40 \mathrm{~F}$.

Acknowledgement. We sincerely wish to express our appreciation to Mrs. K. Minoda for her corporation in carrying out this study. 